Available online at GSC Online Press Directory

GSC Biological and Pharmaceutical Sciences

e-ISSN: 2581-3250, CODEN (USA): GBPSC2

Journal homepage: https://www.gsconlinepress.com/journals/gscbps

(RESEARCH ARTICLE)

\title{
Microhepatic histoarchitecture and liver enzymes evaluation in female lactating Wistar rats treated with metoclopramide and some atypical antipsychotic drugs
}

\author{
Emmanuel NS 1, *, Yahuza M 1, Ejiogu DC 1, Abdulrauf RA 1, Muhammad HD 1, Samaila S 1, Chima CN 1, David \\ $\mathrm{AB}^{1}$, Dange SA ${ }^{1}$, Ishidi IP ${ }^{2}$ and Ogweje $\mathrm{AE}^{1}$ \\ ${ }^{1}$ Department of Human Physiology, Faculty of Basic Medical Sciences, College of Health Sciences, Ahmadu Bello \\ University Zaria, Kaduna Nigeria. \\ ${ }^{2}$ Department of Human Anatomy, Faculty of Basic Medical Sciences, College of Health Sciences, Ahmadu Bello University \\ Zaria, Kaduna Nigeria.
}

Publication history: Received on 14 August 2018; revised on 25 September 2018; accepted on 06 October 2018

Article DOI: https://doi.org/10.30574/gscbps.2018.5.1.0083

\begin{abstract}
This study was designed to evaluate serum liver enzymes and liver histomorphology in lactating female wistar rats following treatment with metoclopramide, olanzapine and risperidone. Twenty (20) female Wistar rats at parturition were divided into four groups of five rats each $(\mathrm{n}=5)$ and treated as follows: Group I: $1 \mathrm{ml} / \mathrm{kg}$ normal saline; group II: 5 $\mathrm{mg} / \mathrm{kg}$ b.w of metoclopramide; group III: $5 \mathrm{mg} / \mathrm{kg}$ b.w of risperidone; group IV: $5 \mathrm{mg} / \mathrm{kg}$ b.w of olanzapine. Administration was carried out orally, once daily at 06:00 $\mathrm{h}$ for a period of ten (10) days. There was a significant increase $(\mathrm{P}<0.05)$ in the serum level of alkaline phosphatase (ALP) in all the treated groups compared to the control thus; metoclopramide $(119.50 \pm 3.66)$, risperidone $(111.00 \pm 5.21)$ and olanzapine $(125.25 \pm 3.07)$. Although there was a significant increase $(\mathrm{P}<0.05)$ in serum level of alanine amino transferase (ALT) in the metoclopramide treated group compared to the control; $(50.25 \pm 1.78)$, the increase in the risperidone treated group (48.06 \pm 4.18$)$ and olanzapine treated group $(44.75 \pm 3.52)$ was not significant. Metoclopramide and risperidone treated groups showed significant increase $(\mathrm{P}<0.05)$ in the serum level of aspartate amino transferase (AST) thus; $(44.75 \pm 2.06)$ and $(44.00 \pm 2.48)$ respectively. In spite of increase in AST level in the olanzapine treated group (42.00 \pm 2.48$)$, it was however not significant. There was no obvious sign of liver damage observed from the histology. In conclusion, treatment with metoclopramide, risperidone, and olanzapine is potentially hepatotoxic, with duration of administration as a determining factor.
\end{abstract}

Keywords: Hepatotoxicity; Metoclopramide; Risperidone; Olanzapine; Lactation

\section{Introduction}

The liver is a large, complex organ that is well designed for its central role in carbohydrate, protein and fat metabolism. It is the site where waste products of metabolism are detoxified through processes such as amino acid deamination, which produces urea [1]. Measurement of liver enzymes remains the most practical tool to diagnose liver damage, and includes mainly alanine aminotransferase ALT), an enzyme present in hepatocytes, and alkaline phosphatase (ALP), an enzyme in the cells lining the biliary ducts of the liver [2]. Dopamine $\mathrm{D}_{2}$ receptor blockade in the brain is a general pharmacodynamic property of all antipsychotics which are mainly of two groups known as 'typical' and 'atypical' antipsychotics [3, 4]. Therefore this study was designed to evaluate serum liver enzymes and liver histology in lactating female wistar rats.

\footnotetext{
${ }^{*}$ Corresponding author

E-mail address: nesolomon@yahoo.com
} 


\section{Material and methods}

\subsection{Chemicals and reagents}

Olanzapine mouth dissolving tablets 5 mg; psychotropics India Ltd; manufacturing license No.: 41/UA/2006, NAFDAC Reg. No.: A4-6722, risperidone tablets $1 \mathrm{mg}$; Stallion laboratories Pvt. Ltd.: Ahmedabad India. manufacturing license No.: G/898, NAFDAC Reg. No.:A4-1677 and metoclopramide hydrochloride tablets $10 \mathrm{mg}$; Jiangsu pengyao pharmaceutical Inc. China, manufacturing License No.: B131205, NAFDAC Reg. No.: 04-6476, normal saline, used for this study were purchased from the Pharmacy of the Ahmadu Bello University Teaching Hospital (ABUTH) Shika; $8 \mathrm{~km}$ away from Samaru on Latitude $112^{\circ} 12^{\prime \prime} \mathrm{N}$ and Longitude $07^{\circ} 37^{\prime \prime}$ E, Zaria Kaduna state, Nigeria.

\subsection{Ethical approval}

Ethical approval was obtained from the Ahmadu Bello University ethical committee on animal use and care, and the research was carried out according to the guidelines of Ahmadu Bello University animal use and care policy.

\subsection{Evaluation of liver enzymes in female lactating Wistar rats}

The thorax of the each anaesthetized animal was cut open and with the aid of a $5 \mathrm{ml}$ syringe, the pulsating heart of the rat pierced at the left ventricle, and blood was aspirated and centrifuged. Sera were obtained for the determination of liver enzymes. Serum alkaline phosphatase was determined at the Department of Chemical pathology, Ahmadu Bello University Teaching hospital using an Auto-analyzer.

\subsection{Histological study of the liver}

The method of Hematoxylin and Eosin staining technique was used for the histological preparation. Liver tissue was harvested on the $10^{\text {th }}$ day from the experimental groups and used for histological study. The method of $\mathrm{H}$ and $\mathrm{E}$ staining technique was used which involved hydrating the tissue sections in descending grades of alcohol from 100\%, 95\%, 90\% and finally $70 \%$ [5]. Each of these steps lasted 3 minutes and the tissues were then washed in running tap water. The tissue were stained with haematoxylin for 25 minutes, washed with water and then differentiated in acid alcohol. The tissue were then counter stained with eosin and blued in Scott water. The tissues were hydrated with ascending grades of alcohol and cleared in xylene for 3 changes in five 5 minutes each. The tissues were mounted with cover slips using a mounting media. The tissues were viewed under a light microscope and the photomicrographs taken.

\subsection{Statistical analysis}

Data obtained from the study were expressed as mean \pm SEM. Statistical analysis was carried out using version 20 of SPSS with the aid of one way analysis of variance (ANOVA) and Tukey's post-hoc test. Values with $(P<0.05)$ were considered significant.

\section{Results}

Table 1 The serum level of liver enzymes in female lactating wistar rats treated with normal saline, metoclopramide, risperidone and olanzapine

\begin{tabular}{|c|c|c|c|}
\hline Treatment & $\operatorname{ALT}(\mu / L)$ & $\operatorname{AST}(\mu / L)$ & $\operatorname{ALP}(\mu / L)$ \\
\hline Control (normal saline) & $36.00 \pm 2.48$ & $33.50 \pm 2.33$ & $88.75 \pm 5.91$ \\
\hline Olanzapine ( $5 \mathrm{mg} / \mathrm{kg}$ ) & $44.75 \pm 3.52^{*}$ & $42.00 \pm 2.48^{*}$ & $125.25 \pm 3.07^{*}$ \\
\hline Risperidone (5 mg/kg) & $50.25 \pm 1.79^{*}$ & $44.75 \pm 2.06^{*}$ & $119.50 \pm 3.66^{*}$ \\
\hline Metoclopramide $(5 \mathrm{mg} / \mathrm{kg})$ & $48.00 \pm 4.18^{*}$ & $44.00 \pm 2.48^{*}$ & $111.00 \pm 5.21^{*}$ \\
\hline
\end{tabular}




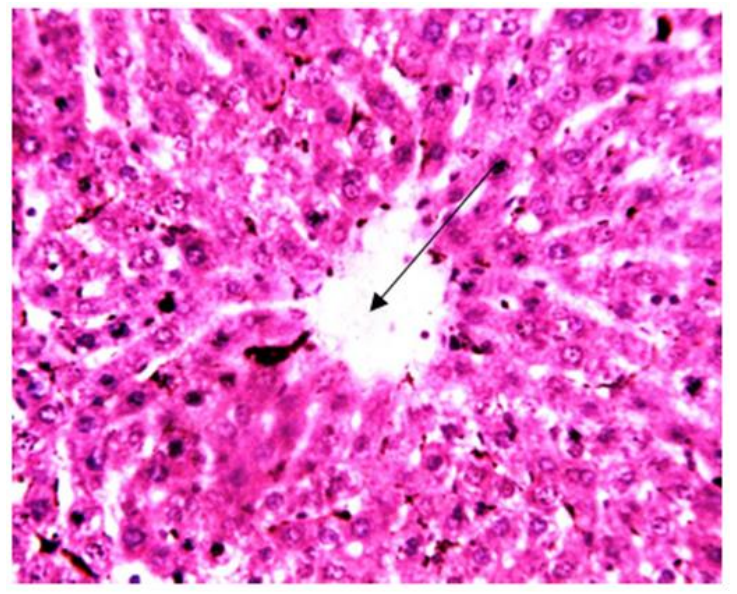

A

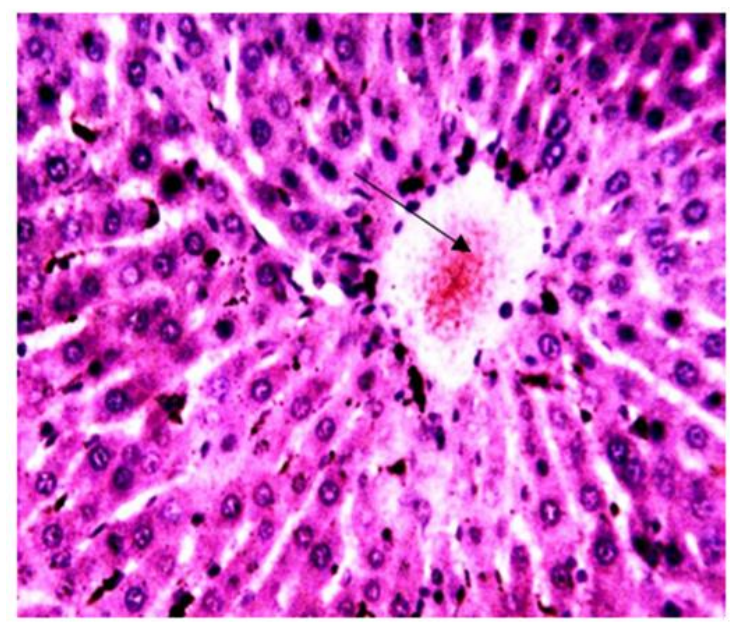

C

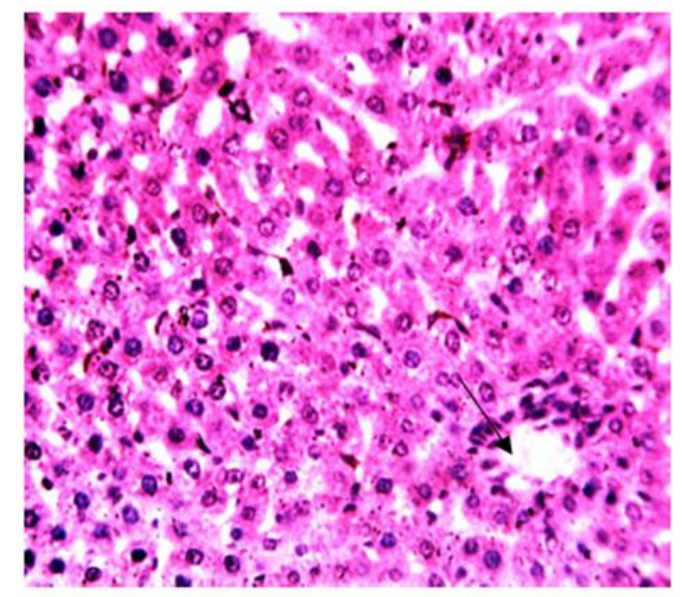

B

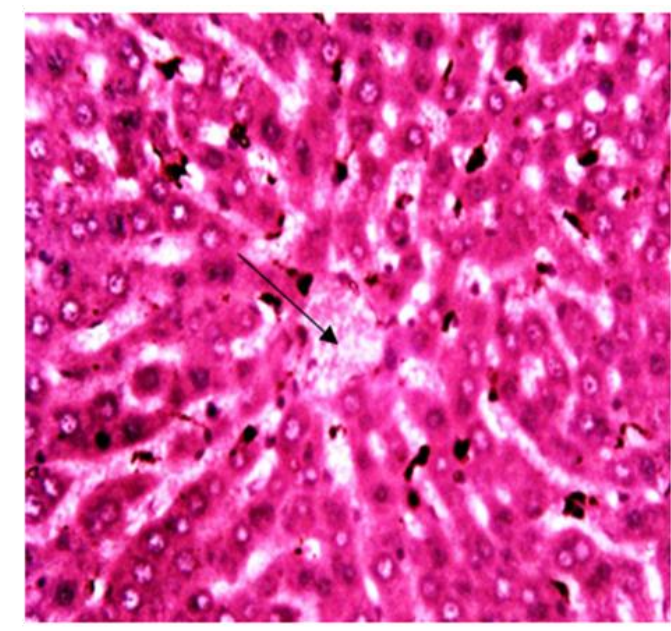

D

Figure 1 The photomicrograph sections of the liver from lactating Wistar rats treated orally with normal saline (A), metoclopramide (B), risperidone (C) and olanzapine (D) for ten (10) days

\section{Discussion}

In this present study, the increase in serum liver enzymes level could have been due to mild damage of the hepatocytes arising from either reactive metabolite formation or reactive oxygen specie formation resulting in lipid peroxidation and subsequent damage of the hepatic cell membranes, hence the leakage of these cytosolic enzymes into the blood. The serum level of aspartate amino transferase in this present study was found to be significantly increased in both metoclopramide and risperidone treated groups when compared with the control group. This result is in concert to that of [6] who conducted a study in non-pregnant subjects. However, there was no significant difference in the olanzapine treated group when compared with the control. The serum level of ALP in this present study was significantly increased in all the treated groups compared to the control. These results could also have been due a form of mitochondrial damage or activation of signal transduction pathways that modulate cell death, all of which could cause the destruction of the hepatocytes resulting in liver enzymes leakage into the blood. The increase were however not excessive. Histopathological studies have been known to help establish casual relationships between drug substances and various pathophysiological responses in the liver. In this present study, there were no visible histological damage of hepatic tissue; such as sinusoidal dilatation, accumulation and proliferation of kupfer cells, glycogen deposits or vacuolated cytoplasm in groups I, II and III. This result could be due to the dosage or the duration of administration which could not have allowed for obvious markers of hepatocytes aggression. The distribution of the liver parenchymal cells appear intact and the central vein structurally functional. However, there was observed sinusoidal dilatations as well as glycogen deposits observed in group IV; treated with olanzapine. The glycogen deposits could have been as a result of increased lipid peroxidation in the hepatocytes resulting in glucose dysfunction. 


\section{Conclusion}

Treatment with metoclopramide, risperidone, and olanzapine has been shown to be potentially hepatotoxic in female lactating Wistar rats from this study. As such, these drugs should be administered with caution.

\section{Compliance with ethical standards}

\section{Acknowledgments}

The authors are grateful to the Faculty of Medical Sciences, Ahmadu Bello University Zaria for their support during this study.

\section{Disclosure of conflict of interest}

The authors declare that there is no conflict of interest.

\section{Statement of ethical approval}

Ethical approval was obtained from the Ahmadu Bello University ethical committee on animal use and care, and the research was carried out according to the guidelines of Ahmadu Bello University animal use and care policy.

\section{References}

[1] Dufour DR, Lott JA, Nolte FS, Gretch DR, Koff RS and Seeff SB. (2000). Diagnosis and monitoring of hepatic injury. I. Performance characteristics of laboratory tests. Clinical Chemistry, 46(12), 2027-49.

[2] [2]. Adams DH, Ju C, Ramaiah SK, Uetrecht J and Jaeschke H. (2010). Mechanisms of immune-mediated liver injury. Toxicological Sciences, 115(2), 307-321

[3] Bennett PN and Allan AJ. (1996). Drugs and Human Lactation: A Comprehensive Guide to the Content and Consequences of Drugs, Micronutrients, Radiopharmaceuticals, and Environmental and Occupational Chemicals in Human Milk. Elsevier, 23.

[4] Bymaster F, Perry KW Nelson DL, Wong DT, Rasmussen K and Moore NA. (1999). Olanzapine: a basic science update. British Journal Psychiatry, 37, 36-40.

[5] Laporta J, Peters TL, Merriman KE, Vezina CM and Hernandez LL. (2013). Serotonin (5-HT) Affects Expression of Liver Metabolic Enzymes and Mammary Gland Glucose Transporters during the Transition from Pregnancy to Lactation. PLoS ONE, 8(2), 57847

[6] Atasoy N, Erdogan A, Yalug I, Ozturk U, Konuk N, Atik L and Ustundag Y. (2007). A review of liver function tests during treatment with atypical antipsychotic drugs: a chart review study. Prognostic Neuropsychopharmacoly Biology Psychiatry, 31(6), 1255-1260.

\section{How to cite this article}

Emmanuel NS, Yahuza M, Ejiogu DC, Abdulrauf RA, Muhammad HD, Ogweje AE, Chima CN, David AB, Dange SA, Ishidi IJ and Samaila S. (2018). Microhepatic histoarchitecture and liver enzymes evaluation in female lactating Wistar rats treated with metoclopramide and some atypical antipsychotic drugs. GSC Biological and Pharmaceutical Sciences, 5(1), 115-118. 